\title{
Analysis of Current Situation and Issues of Intelligent Logistics in China
}

\author{
Rong Jia* \\ Office of Planning \& Finance \\ Chongqing University of Science and Technology \\ Chongqing 401331, China \\ Email: jiarong71@126.com
}

\author{
Weijia Peng \\ School of Business \\ Chongqing City Management College \\ Chongqing 401331, China \\ Email: 3182314497@qq.com
}

\begin{abstract}
Driven by new technologies such as the Internet of things, big data and artificial intelligence, intelligent logistics has developed rapidly, effectively boosting the competitiveness of enterprises and bringing great convenience to people's lives. Based on the introduction of related concepts of intelligent logistics, this paper analyzes the relevant policies and current situation of intelligent logistics in China, and makes a beneficial discussion on the system architecture, application cases, industrial chain, information security, personnel training and other aspects of intelligent logistics. It is concluded that the sustainable development of intelligent logistics needs close cooperation of policies, enterprises, technologies, talents, infrastructure and other aspects.
\end{abstract}

Keywords-Intelligent Logistics; Internet of Things; Big Data; Artificial Intelligence; Information Security; Talent Training

\section{INTRODUCTION}

China's express delivery industry has witnessed rapid development in recent years. According to the data released by the website of the State Post Bureau, the total number of express delivery in China has exceeded 50 billion in 2018, with a year-on-year growth of more than 26 percent. The express delivery development index in 2018 was 814.5 , with a year-on-year growth of 23.6 percent. At the same time, from the 2018 Courier group insight report, according to data from 2016 to 2018, the number of Chinese couriers increased by $50 \%$ to 3 million, but the high turnover rate of express industry personnel, resulting in a prominent contradiction between the end of logistics human resource gap and the huge volume of express industry, especially in the field of artificial intelligence in the logistics industry. In addition, the rising cost of each link of the whole logistics system has led to the urgent demand for intelligent logistics, and has become the internal driving force for the transformation and upgrading of traditional logistics enterprises. In addition, the rising cost of each link of the whole logistics system has led to the urgent demand for intelligent logistics, and has become the internal driving force for the transformation and upgrading of traditional logistics enterprises.

The concept of Intelligent Logistics System (ILS) originated from the research report intelligent future supply chain published by IBM, which talks about the "Intelligent supply chain" that uses sensors, GPS and other data to generate real-time data. With the "perception of China" strategy put forward in 2009 , Internet of things technology has been vigorously developed and promoted in all walks of life across the country. In the same year, the information center of China Logistics Technology Association and other units jointly put forward the concept of "intelligent logistics" in the logistics industry. In general, we believe that "intelligent logistics" refers to the transformation and upgrading of traditional systems and the construction of a digital and intelligent logistics system of the whole industrial chain with the help of corresponding information technology and equipment, such as intelligent sensing equipment, Internet technology, cloud computing technology, modern communication technology, big data analysis technology, etc., which has a higher degree of automation than traditional systems. It has the advantages of intelligent reliability, higher management efficiency and lower enterprise cost.

In this paper, in Section II, we firstly analyze the relevant policies and development status of intelligent logistics in China, and then make beneficial discussions on the system architecture in Section III, industrial chain in Section IV, information security in Section $\mathrm{V}$, and personnel training and other issues involved in the intelligent logistics system in Section VI. The last Section is conclusions.

\section{Relevant Policies And CurRent Situation of INTELLIGENT LOGISTICS}

In order to improve the development level of logistics industry, China has issued relevant policies, especially the industry planning and policy guidance of intelligent logistics. In August 2011, opinions on policies and measures to promote the healthy development of the logistics industry were issued, proposing to strengthen independent research and development of new technologies such as intelligent transportation, cargo tracking, logistics information platform and management, and emphasizing the role of information technology in the logistics system. In September 2014, the medium and long term logistics development plan (20142020) was issued, proposing to basically establish a modern logistics service system featuring advanced technology, green environment protection, safety and order by 2020 . In February 2017, the 13th five-year plan for the development of express industry was released to encourage express companies to promote and adopt advanced technologies and equipment such as robots and drones. In July 2017, the new generation of artificial intelligence development plan was released, which takes cultivating high-end and efficient 
intelligent economy as one of the key tasks, promotes the integration and innovation of artificial intelligence and various industries, and a batch of pilot demonstration of artificial intelligence applications represented by intelligent logistics will become a new power to accelerate the upgrading of industrial intelligence. In October 2017, the guidance on actively promoting supply chain innovation and application was released, which proposed to accelerate the application of human-computer intelligent interaction, industrial robots, intelligent factories, intelligent logistics and other technologies and equipment. Recently, in January 2018, the opinions on promoting the coordinated development of ecommerce and express logistics were issued, proposing to fully implement the "Internet plus circulation" action plan and strengthen the use of Internet of things, big data, robotics and other technologies and equipment in the logistics industry.

With the strong guidance of national policies and the continuous reliance of industrial enterprises on scientific and technological innovation, a large number of logistics facilities are connected to the network with the help of mobile Internet and various perception sensors. In addition, with the substantial increase of logistics transaction volume, a huge amount of transaction data has been generated. The data-driven business model has given birth to the industrial intelligent transformation, which has effectively promoted the rapid development of intelligent logistics in China.

According to relevant statistical data, in 2018, the market scale growth of China's intelligent logistics exceeded 400 billion yuan, with a year-on-year growth of $20.4 \%$. It is predicted that the market scale will exceed 500 billion yuan by 2020 and trillion yuan by 2025. There are many leading enterprises in intelligent logistics industry, such as Sinotrans, JD Logistics, SF Technology, Cainiao Network, etc. At present, there is still a big gap between the development level of China's intelligent logistics and that of developed countries, such as weak and backward logistics infrastructure, logistics related technology, logistics automation, lack of scientific and efficient management capacity, and lagging behind in the standardization of logistics information [1].For example, the 2019 edition of the logistics standards catalogue manual has collected 1093 items of the current logistics national standards, industry standards and local standards that have been promulgated in China [2], while there are about 2,500 logistics related standards in the UK and 2480 logistics related standards in Germany. For another example, there is also a big difference in the low-carbon technology of intelligent logistics. According to the data of xinhuanet, the fuel consumption of freight cars in China is nearly twice that of developed countries per 100 ton kilometers.

Hence, we need to continue to innovate and strengthen policy guidance, and increase the education chain and talent chain. The in-depth integration of talent chain, industrial chain and innovation chain promotes the sustainable and rapid development of China's intelligent logistics.

\section{INTELLIGENT LOGISTICS SYSTEM ARCHITECTURE}

The development of intelligent logistics cannot be separated from technological innovation and the support of big data. In 2013, McKinsey Global Research Institute released a research report, which mentioned 12 disruptive technologies that may affect human life, business and economy in 2025. Among them, the top 5 technologies such as mobile Internet, brain labor automation, Internet of things, cloud computing technology, advanced robots are closely related to intelligent logistics. In the future, modern logistics must be an intelligent logistics integrating key technologies such as big data, artificial intelligence, robotics, Internet of things and cloud computing. It can also simulate part of human intelligence and has the ability of perception, learning, reasoning and judgment as well as solving some problems in logistics by itself.

The architecture of intelligent logistics [3] is shown in Fig.1, which has four layers, namely, perception layer, network transmission layer, data storage layer and application service layer. Each layer is supported by different means of information technology. For example, the core technologies involved in the sensing layer include sensor technology, RFID technology, global positioning system (GPS), micro electro mechanical system (MEMS), image recognition technology, etc. The core technologies involved in the transmission layer include various communication technologies and network technologies, such as WiFi, ZigBee, 3G / 4G / 5G, GPRS, radio and television network, China's next generation networks (NGB), etc. The core technologies involved in the top application layer include cloud computing, data mining, artificial intelligence, machine learning, etc.

In [4], the related technologies, system framework and development mode of intelligent logistics are analyzed, and several typical application cases are given. For example, the design of sorting system for express delivery enterprises based on the mechanical arm with visual recognition [7], another example is the application of Internet of things technology in Delta Airlines [8].

\section{INTELLIGENT LOGISTICS INDUSTRY CHAIN}

The intelligent logistics industry chain is divided into three fields: warehousing, transportation and distribution. The warehousing field mainly includes four major technologies and applications: automatic three-dimensional warehouse such as three-dimensional storage, shuttle bus, etc., warehouse robot and automation equipment such as joint robot, arm robot, AGV robot, etc., wearable equipment such as smart glasses, VR augmented reality, etc. and cargo identification such as RFID tag, two-dimensional code tag, etc., transportation field includes vehicle cargo matching, Driverless, fresh and cold chain, etc. The distribution field includes unmanned distribution machine, intelligent express cabinet, etc.

On the whole, China's logistics industry needs to strengthen the construction of "connectivity", especially among small and medium-sized logistics enterprises, there are still information barriers in each link of the logistics chain, the degree of collaborative sharing of information is not high, even some information is not connected, which seriously restricts the integrated development of logistics. It is necessary to carry out systematic and scientific planning for logistics system, fully integrate advanced technologies such as Internet of things, big data, cloud computing and artificial intelligence into all logistics links, strengthen the formulation and promotion of logistics standards, open up the information island in the industrial chain within and between enterprises, organically integrate and share the information in the three fields of warehousing, transportation and distribution, and improve enterprises. The production 
efficiency and flexibility of the industry shall be increased, the product inventory and production cost shall be reduced, the competitiveness of the enterprise shall be improved, and the customer consumption experience shall be improved.

\section{INTELLIGENT LOGISTICS INFORMATION SECURITY}

Because intelligent logistics has the characteristics of "digital drive" and "collaborative sharing”, among which the logistics business under B2C mode is closely related to the majority of consumers. People put forward higher requirements for timeliness, visualization and reliability of logistics, and the problem of personal information disclosure has become increasingly prominent. For example, the awareness of protecting personal information such as user's name, address and telephone is still weak, and the technical means adopted are relatively elementary. Therefore, information security has become a problem that intelligent logistics must attach great importance to. We can take effective measures from strengthening the management of online shopping platform and logistics enterprises, strengthening the internal system construction of enterprises, strengthening the government supervision, promulgating corresponding laws and regulations, updating information protection technology means to protect the security of personal information as much as possible [5]. For example, within the validity period of a logistics order, virtual telephone technology can be used for reference to effectively avoid the leakage of users' real telephone. Highstrength cryptography such as PKI public key cryptography, elliptic curve cryptography, chaos cryptography, quantum cryptography, DNA cryptography, and biometric technology are adopted to encrypt and protect key information in the logistics system to prevent leakage and tampering.

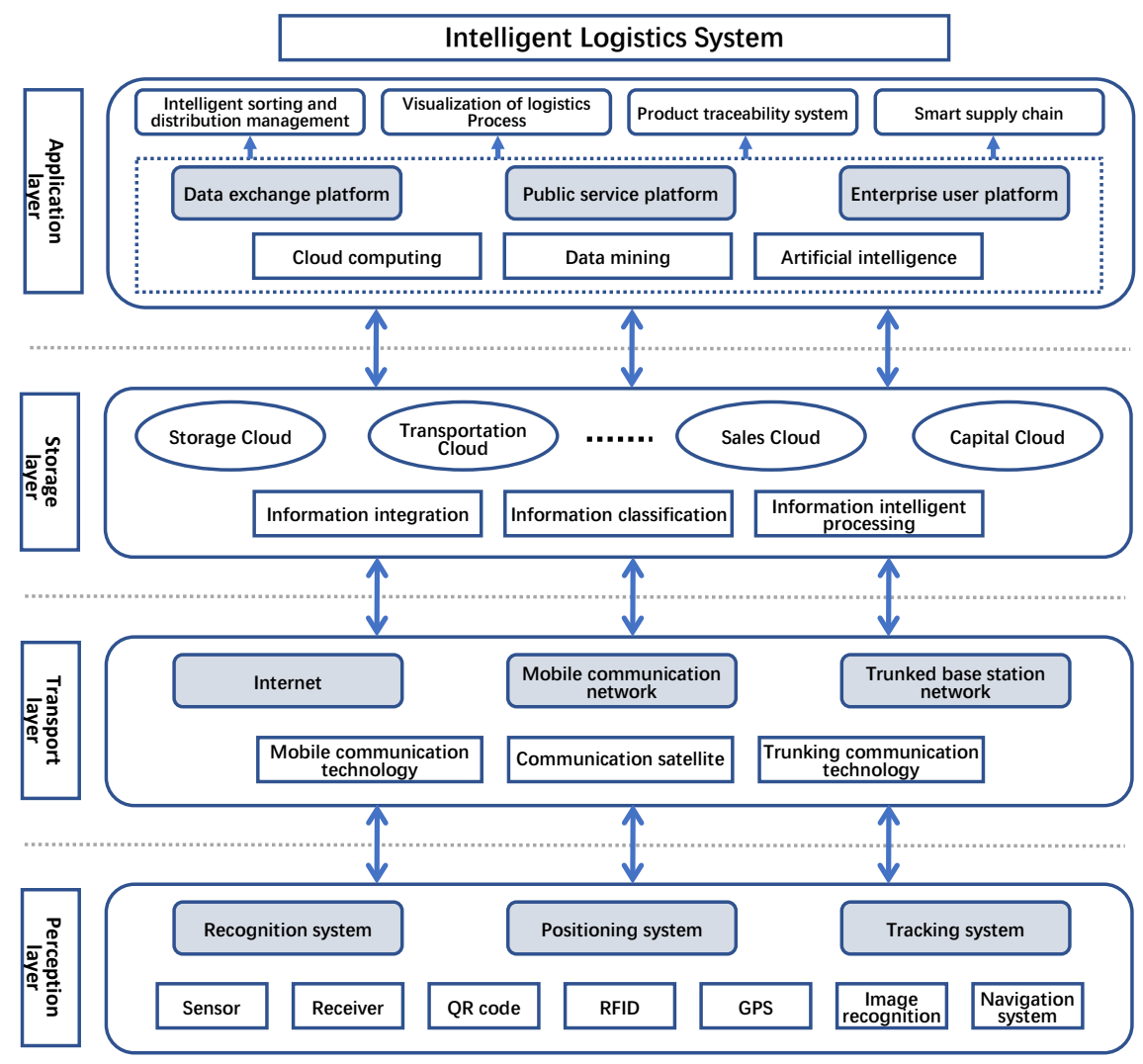

Fig.1. Architecture of intelligent logistics system.

\section{Cultivation of InTELligent LOGistics TALENTS}

China's intelligent logistics is in its infancy and showing a rapid development trend. Many companies, such as JD, SF, Suning and Cainiao, have begun to try in the frontier fields of Internet of things, intelligent perception, big data, artificial intelligence, driverless, unmanned storage, unmanned distribution, logistics robots, etc., which requires intensive investment of technology, talents and capital.

At present, there is a great lack of talents in China's logistics industry, especially the senior management talents at the production site, as well as the comprehensive talents who understand the new trends of logistics at home and abroad and have international vision. In addition, the competition for cross-border talent resources intensifies the competition among enterprises in the logistics industry.
Intelligent perception, AI and big data analysis algorithm are the basis of realizing intelligent logistics. The most important thing for future logistics system is to have a group of scientists who understand algorithm design, rather than a large number of robots [6].

In order to cope with the shortage of talents, China should increase the training of logistics professionals at all levels. First of all, colleges and universities should strengthen school-enterprise cooperation with enterprises to create a good ecology of industry-education integration and collaborative education, and carry out all-round cooperation in the aspects of talent training program formulation, curriculum system construction, teacher training, training and practice base construction, professional laboratory construction, education and teaching research reform, etc. Second, universities should think about how the Internet of 
in this study is partly supported by Research Foundation of Chongqing University of Science and Technology.

\section{REFERENCES}

[1] W. Chen, "Comparison and Experience of the Development of Intelligent Logistics between China and Foreign Countries," Practice in Foreign Economic Relations and Trade, vol. 6, pp. 86-89, 2016.(In Chinese)

The development of intelligent logistics has brought many benefits to the society, such as reducing the production cost of enterprises, reducing the waste of resources, improving the ecological environment, and improving the productivity of enterprises. With the support of big data, cloud computing, artificial intelligence, information security, robotics and other technologies, intelligent logistics takes into account convenience, reliability, security and intelligence to build a modern logistics system and provide people with an unprecedented logistics experience. The sustainable and rapid development of intelligent logistics requires the careful division of labor and close cooperation of all sectors of society, the guidance of government policies, the continuous innovation of enterprises and the continuous supply of talents.

\section{ACKNOWLEDGMENT}

The authors would like to thank the anonymous reviewers for their valuable suggestions. The work described
[2] Manual of logistics standard catalogue in China (the 2019 Edition), http://www.sac.gov.cn/, 2019. (In Chinese)

[3] P. D. Fu, "Construction of Intelligent Logistics Mode Based on Big Data Technologies,” Logistic Technology, vol. 1, pp. 135-139, 2018. (In Chinese)

[4] B. Yang, Y. P. Du, L. Zhu, G. Y. Liu, Y. Zhang, "New Technology Application and Case Analysis in Intelligent Logistics System," Green Packaging, no.6, pp. 35-44, 2019. (In Chinese)

[5] K. Y. Zhu, "Analysis of Personal Information Security in Logistics Industry," Logistics Engineering and Management, vol. 42, no. 7, pp. 164-165,169, 2019. (In Chinese)

[6] W. B. Wang, "The Next Five Years is the Acceleration Period of Intelligent Logistics,” http://www.sohu.com/a/143779740_464103, 2017. (In Chinese)

[7] W. Xu, Z. Le, Z. Yuan, et al. "Research and Development of Target Recognition and Location Crawling Platform based on Binocular Vision,” Materials Science and Engineering Conference Series, 2018.

[8] Y. D. Liu, "Application of GPS Technology in Airport Construction and Operation Management,” Airport Construction, no. 1, pp. 23-25, 2008. (In Chinese) 